\title{
CORRESPONDENCE
}

\begin{abstract}
We welcome letters to the Editor concerning articles which have recently been published. Such letters will be subject to the usual stages of selection and editing; where appropriate the authors of the original article will be offered the opportunity to reply.

Letters should normally be under $\mathbf{5 0 0}$ words in length, double-spaced throughout, signed by all authors and fully referenced. The edited version will be returned for approval before publication.
\end{abstract}

Sir,

\section{RESECTION OF THE FIBULA}

We were interested to read the paper 'Donor site morbidity following resection of the fibula' by Lee et al (72-B:129-31, January 1990) which reported a definite incidence of symptoms and of motor weakness in the donor leg after the transfer of a vascularised fibular graft. It is possible that with increasing length of follow-up more morbidity will become apparent (Youdas et al 1988). We report a patient with a different long-term complication and reinforce the conclusions of Lee et al.

A 23-year-old man sustained a Gustilo grade IIIA fracture of his right tibia. Two years after initial internal fixation, a free vascularised fibular transfer was performed for nonunion. Sound union was achieved.

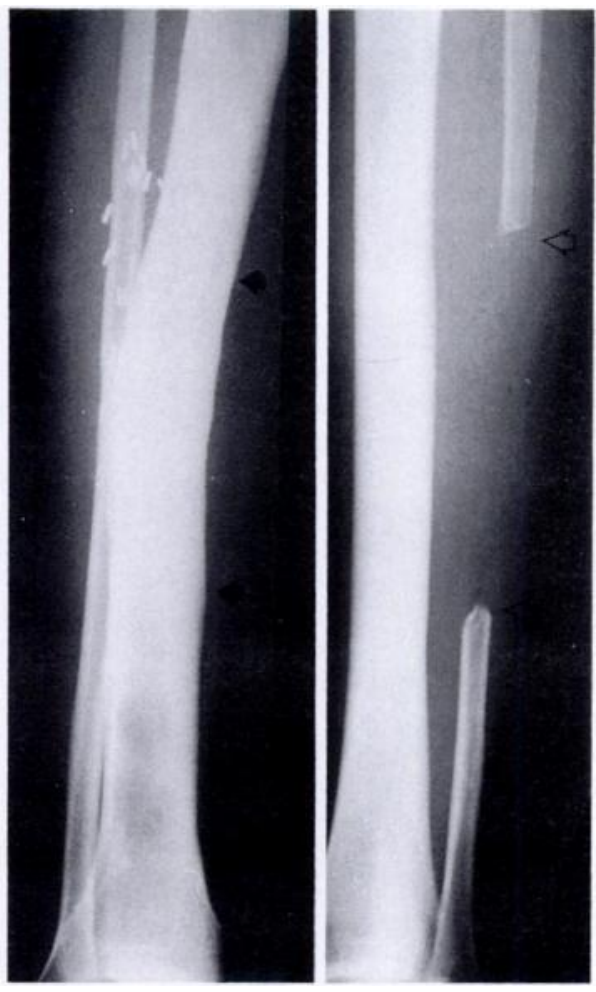

Fig. 1

(C) 1991 British Editorial Society of Bone and Joint Surgery 0301-620X/91/2155\$2.00

J Bone Joint Surg [Br] 1991; 73-B:352-4.
At review nine years after his accident, the patient complained of persisting soreness and discomfort in the foot of the left (donor) leg. Clinically he had solid union of his right tibia (Fig. 1) but in the donor leg there was a tenodesis of the flexor digitorum longus. This produced flexion of the lateral four toes when the ankle was dorsiflexed during the swing phase of walking. Gait analysis using the VICON system showed no significant abnormality. It would appear that the tenodesis was due to fibrosis or ischaemia secondary to the dissection of his graft.

We agree with the conclusion of Lee et al that informed consent for this operation should include mention of possible morbidity in the donor. In our opinion this is a price that most patients will be willing to pay in order to regain function in the injured limb.

S. ROBBINS, FRCS Ed

Registrar in Plastic Surgery,

The London Hospital,

Whitechapel,

London E1 1 BB.

B. N. BAILEY, FRCS

Consultant Plastic Surgeon (Retired),

Stoke Mandeville Hospital,

Aylesbury,

Buckinghamshire HP21 8AL.

Lee EH, Goh JCH, Helm R, Pho RWH. Donor site morbidity following resection of the fibula. J Bone Joint Surg [Br] 1990; 72-B:129-31.

Youdas JW, Wood MB, Cahalan TD, Chao EY. A quantitative analysis of donor site morbidity after vascularized fibula transfer. $J$ Orthop Res 1988; 6:621-29.

\section{PULSED ELECTROMAGNETIC FIELDS}

Sir,

The paper by W. J. W. Sharrard (72-B:347-55, May 1990) concerns us in a number of respects:

1. Commercial involvement? We are surprised that your journal does not provide a conflict of interest statement to enable the reader to know that Electro-Biology Inc (EBI), the company which manufactures the field generator used, was intimately involved in the study and also prepared the trial protocol. In this, EBI reserved to itself the sole right to terminate the study at its own discretion and the right of submitting and promoting publication of the results in collaboration with the investigators. The protocol also prescribed that the treatment code would be 'known only by EBI (US) research personnel'. To ensure independence it would be usual for a third party to hold the code and 